\title{
LETTER
}

\section{The Global Alliance against Respiratory Diseases (GARD) Country Report}

*Arzu Yorgancioglu', Alvaro A Cruz², Jean Bousquet ${ }^{3}$, Nikolai Khaltaev $^{4}$, Shanti Mendis ${ }^{4}$, Alexander Chuchalin ${ }^{5}$, Eric D Bateman 6 , Paulo Camargos ${ }^{7}$, Niels H Chavannes ${ }^{8}$, Chunxue Bai ${ }^{9}$, Diana Deleanu ${ }^{10}$, Vitezslav Kolek ${ }^{11}$, Piotr Kuna ${ }^{12}$, Giovanna Laurendi' ${ }^{13}$, Mohammed Reza Masjedi ${ }^{14}$, Sonia Mele ${ }^{13}$, Florin Mihaltan ${ }^{15}$, José Rosado Pinto ${ }^{16}$, Boleslaw Samolinski ${ }^{12}$, Giselda Scalera ${ }^{13}$, Talant Sooronbaev ${ }^{17}$, Mohamed Awad Tageldin ${ }^{18}$, Le Thi Tuyetlan ${ }^{19}$, Osman Yusuf² ${ }^{20}$ Cezmi Akdis ${ }^{21}$, Abay Baigenzhin ${ }^{22}$, Carlos Baena Cagnani ${ }^{23}$, Monica Fletcher ${ }^{24}$, Bilun Gemicioglu ${ }^{25}$, Yousser Muhammed ${ }^{26}$, Hironori Sagra ${ }^{27}$, Teresa To ${ }^{28}$, Antje-H Fink Wagner ${ }^{29}$

${ }^{1}$ Celal Bayar University Department of Pulmonology, Manisa, Turkey

2 ProAR - Nucleo de Excelencia em Asma, Federal University of Bahia, Brasil

${ }^{3}$ University Hospital and INSERM, Hopital Arnaud de Villeneuve, Montpellier, France,

${ }^{4}$ WHO/GARD Secretariat, Geneva, Switzerland,

${ }^{5}$ Pulmonolory Research Institute FMBA Russia

${ }^{6}$ Division of Pulmonology, Department of Medicine, University of Cape Town, Cape Town, South Africa.

${ }^{7}$ Federal University of Minas Gerais, Belo Horizonte Brazil

${ }^{8}$ Leiden University Medical Center, Department of Public Health and Primary Care, Leiden, The Netherlands.

9 Department of Pulmonary Medicine, Zhongshan Hospital, Fudan University, China

${ }^{10}$ Romanian Society of Allergology

${ }^{11}$ Dept. of Respiratory Medicine I.P.Pavlova, Czech Republic

${ }^{12}$ Polish Society of Allergology, Poland

${ }^{13}$ Ministero della Salute, Italy

${ }^{14}$ Masih Daneshvari hospital, DarAbad, Tehran, Iran

${ }^{15}$ National Institute Of Pneumology M.Nasta Romania

${ }^{16}$ Immunoallergology Department, Hospital da Luz - Lisboa, Portugal

${ }^{17}$ Kyrgyz Thoracic Society, Bishkek, Kyrgyzstan

${ }^{18}$ Ain Shams Faculty of Medicine, Abassia, Cairo, Egypt

${ }^{19}$ UMC, University of Medicine and Pharmacy Hochiminh city, Vietnam

${ }^{20}$ The Allergy and Asthma Institution Pakistan

${ }^{21} \mathrm{EAACl}$, Switzerland

${ }^{22}$ GARD Kazakhstan Coordinator

${ }^{23}$ Catholic University of Cordoba, Argentina,

${ }^{24}$ Education For Health Warwick, UK

${ }^{25}$ Cerrahpaia University Department of Pulmonolgy Istanbul, Turkey

${ }^{26}$ GARD Syria Coordinator

${ }^{27}$ GARD Japan Coordinator

${ }^{28}$ The Hospital for Sick Children and Dalla Lana School of Public Health, University of Toronto, Toronto, Ontario, Canada

${ }^{29} \mathrm{GAAP}$, Austria

\section{*Correspondence: Dr Arzu Yorgancioglu, Celal Bayar University, School of Medicine Dept of Pulmonology, Manisa, Turkey \\ Tel: +90 5322656277 Fax: +90 2362328492 \\ E-mail:arzuyo@hotmail.com}

Received 20th September 2013; re-submitted 25th November 2013; revised 28th January 2014; accepted 28th January 2014; online 25th February 2014 (C) 2014 Primary Care Respiratory Society UK. All rights reserved http://dx.doi.org/10.4104/pcrj.2014.00014

\section{Dear Sirs,}

The Global Alliance against Respiratory Diseases (GARD) is a network within the World Health Organization (WHO), comprising representatives of national and international organisations, institutions and agencies, all of whom are working towards the common goal of improving global lung health..$^{1-3}$ GARD aims to increase worldwide recognition of the importance of Chronic Respiratory Diseases (CRDs) as one of the most important health problems globally, and also aims to establish cooperation between 
countries and GARD member organisations in improving programmes for the prevention and management of CRDs. ${ }^{2,3}$

GARD was formed almost a decade ago, and since then there have been many successes, particularly at country level (see Table 1). There has indeed been increased recognition of the importance of chronic diseases, as demonstrated by the United Nations Summit on Chronic Diseases held in 2012, during which CRDs - along with cardiovascular diseases, diabetes and cancers - were recognised as major priorities.

However, in many countries there has been reluctance to engage with local GARD champions in establishing local initiatives. One reason for this is a preference for national health services to devise strategies that include other chronic diseases, and in many countries there appears to be a lack of political will to commit to effective CRD prevention and control measures. Nevertheless, local GARD champions - many of whom are national and international leaders in respiratory and allergic disease professional medical societies - continue to be key activists for the formation of effective programmes.

Current projects vary in different countries according to country-specific needs and the level of engagement of government health departments. Where government involvement is strong, as in Turkey, Italy and Portugal, ${ }^{4-6}$ progress has been considerable. In Italy, Portugal, Kyrgyzstan, Russia and Turkey, GARD has played a significant role in assisting the development of national CRD control programmes. However, in other countries the GARD-supported programmes are more limited, being either disease-specific or restricted to certain geographical regions. In 2012, GARD played an important role in helping to establish the Portuguese National Programme on Respiratory Diseases. ${ }^{6}$ The Dutch GARD leadership succeeded in convincing the government to develop a SMARTformulated collaborative National Action Programme on CRDs. ${ }^{7}$ In the Czech Republic, GARD leaders launched CARO (Czech Alliance against Chronic Respiratory Diseases), leading to the formation of a National Programme by the Ministry of Health in 2008. GARD Brazil has made significant strides in including a guideline for prevention and management of asthma, rhinitis and COPD in primary health care programmes, and has implemented a pilot project utilising the Practical Approach to Lung Health (PAL); in addition, access to free inhalers for patients with asthma has increased throughout the country. ${ }^{8}$

GARD has four strategic objectives: advocacy; partnership; national plans; and surveillance. For each objective, expected outcomes, indicators, milestones and core activities have been established.

\section{Advocacy}

The majority of countries have focal points within their governmental health departments, usually the officer in the health ministry responsible for NCDs. Obtaining and maintaining ongoing ministerial endorsement is a problem in some countries since governments can change frequently and rapidly, causing changes in health policy and national priorities.

\section{Partnership}

GARD's policy is to develop and maintain a network of collaborative partnerships with different parties, which then helps with both human and financial resources. The number of collaborating parties in different countries varies, and is highest in Turkey (58 parties), Italy (42), the Netherlands (34), Czech Republic (21), Portugal (18), Iran (13) and Krygyzstan (12). Funding models also vary. In Turkey and Italy, GARD projects are funded by the Ministry of Health, and in the Netherlands there is substantial government funding. In most other countries, GARD activities are funded by a variety of sources including non-governmental organisations (NGOs), pharmaceutical companies and the private sector.

\section{National plans}

The expected outcome for national plans is a strengthening of existing initiatives for CRDs and the adoption of multisector national policies which conform to the WHO Action Plan for NCDs (see Table 1). GARD Turkey is a good example of this integration. ${ }^{9}$ In Turkey's national plans, not only were CRDs included in the NCD plans, but the GARD-affiliated CRD experts led the development of an NCD network that established the national plan. In Italy, planning innovation required confrontation of issues that threaten public health ${ }^{4}$ In the Netherlands, their national programme aims to reduce hospitalisation days, productivity loss, adolescent smoking, and mortality due to asthma and COPD.7 South Africa's plan included development of an integrated care clinical practice guideline for asthma, COPD, TB and pneumonia, as well as a training programme for primary care nurses and doctors; initially called Practical Approach to Lung Health South Africa (PALSA PLUS), the South African programme is now called PC101 and has been adopted by the Ministry of Health for national roll-out. ${ }^{10}$ Integrated Care Pathways for Airway Diseases (AIRWAYS-ICPS) is a GARD demonstration project approved by the European innovation Partnership on Active and Healthy Ageing (DG Sanco and CNECT, European Union).

\section{Surveillance}

Expected outcomes are the development of a WHO framework for evaluating CRDs, collection of epidemiological information, identification of knowledge gaps, and the development of costeffective interventions. ${ }^{2}$ A further outcome is the proportion of participating countries whose information on CRDs is reported to WHO and subsequently published. Using national ministry of health data, information and analysis from two countries, Turkey ${ }^{5,9}$ and Italy4, has already been published.

To date, GARD's major achievements have been the launch of national GARD-led initiatives and a variety of projects in partnership with government health departments, as exemplified by GARD's role in Turkey, Portugal and Italy. Arguably, GARD's greatest achievement has been its ability to forge collaborative partnerships and develop a shared vision with a large number of parties including professional medical societies, patient organisations, medical and pharmaceutical companies, NGOs, governments, and WHO, in order to address chronic respiratory diseases and allergy worldwide. Preventing and controlling CRDs, and keeping them on the global health agenda, will require the ongoing energies of all involved in GARD. 
Table 1. GARD Country Plans

COUNTRY GARD COUNTRY PLANS

\begin{tabular}{|c|c|}
\hline BRASIL $^{8}$ & $\begin{array}{l}\text { Persuade health authorities in all levels (country, provinciale and municipal) to plan and implement a CRDs program in collaboration } \\
\text { with local stakeholders }\end{array}$ \\
\hline \multirow[t]{3}{*}{ CZECH REPUBLIC } & Support co-operation between pneumologists and allergologists; \\
\hline & Organize international events on CRD (for example, World Spirometry Day) \\
\hline & Increase patient education (CARO launched a publication on respiratory disorders for patients) \\
\hline \multirow[t]{3}{*}{ CHINA } & Encourage educational activities for doctors, patients and the wider community \\
\hline & Establishment of an e-medicine service \\
\hline & Arrange congresses and seminars for respiratory physicians \\
\hline \multirow[t]{2}{*}{ EGYPT } & Undertake studies on the prevelance of COPD in Egypt \\
\hline & Implement guidelines for the diagnosis and management of COPD including campaigns for tobacco control \\
\hline IRAN & Plans to assess the current status for NCD/CRDs before developing a programme \\
\hline ITALY ${ }^{4}$ & Promotion of lung health and raising the level of public awareness on respiratory hazards. Several other initiatives have begun. \\
\hline \multirow[t]{2}{*}{ KYRGYZSTAN } & $\begin{array}{l}\text { The GARD National Action Plan 2008-2012 was developed and published in the Official Journal of the Euro-Asian Respiratory Society } \\
\text { "Respiratory Medicine" and a report has been presented to the Ministry of Health. }\end{array}$ \\
\hline & $\begin{array}{l}\text { The integrated plan for prevention and control of CRD by the MoH 2013-2016 in development with participation by the Deputy Minister } \\
\text { of Health. This will be integrated into the National Program of control of NCD 2013-2016. }\end{array}$ \\
\hline \multirow[t]{6}{*}{ NETHERLANDS ${ }^{7}$} & Dutch National Action Programme on Chronic Lung Diseases: Objectives are to achieve the following; \\
\hline & 1) $25 \%$ reduction in hospitalisation days for asthma and COPD \\
\hline & 2) $15 \%$ reduction in lost working days due to asthma and COPD \\
\hline & 3) $20 \%$ improved cost-effectiveness of inhalation medication \\
\hline & 4) $25 \%$ reduction of adolescents taking up smoking \\
\hline & 5) $10 \%$ reduction of mortality due to asthma and COPD \\
\hline \multirow[t]{3}{*}{ PAKISTAN } & 1GARD Projects include 1. A study of Airborne Allergens in Islamabad \& Rawalpindi. 2. Free Pollen Allergy Camp in Islamabad, with Chief \\
\hline & Commissioner, Islamabad Capital Territory. 3. Training of Primary Care Physicians in Allergy \& Asthma Management. 4. National Aeroallergen \\
\hline & Study \\
\hline POLAND & National Programme of Early Diagnostics and Treatment of Asthma "POLASTMA" \\
\hline PORTUGAL ${ }^{6}$ & $\begin{array}{l}\text { During the first years, 2007-2011, the major aim of GARD was the integration, participation and dissemination of activities from } \\
\text { governamental and non-governamental organizations (18) linked to CRD. Since } 2012 \text { GARD has been part of the new National } \\
\text { Programme on Respiratory Diseases supported by the } \mathrm{MoH} \text {. }\end{array}$ \\
\hline ROMANIA & $\begin{array}{l}\text { GARD initiatives are; } \\
\text { 1. Study the prevalence of COPD } \\
\text { 2. Organise training courses in somnology, smoking cessation, functional testing } \\
\text { 3. Provide e-learning training on } 8 \text { hot topics including chronic obstructive diseases } \\
\text { 4. Provide courses on the Romanian Society of Pneumology-on Update GOLD } \\
\text { 5. Perform studies to determine the national prevalence of } \\
\text { 6. Perform studies on compliance of patients with COPD Management - COPD360 }\end{array}$ \\
\hline SOUTH AFRICA & $\begin{array}{l}\text { Adaptation and nationwide implementation of the Practical Approach to Lung Health in South Africa (PALSA Plus) and Primary Care } 101 \\
\text { (PC101) in all DOH primary care facilities }\end{array}$ \\
\hline TURKEY 5 & $\begin{array}{l}\text { GARD Turkey Project (National control program and action plan on Chronic Airway Diseases (Asthma \& COPD) } \\
\text { 1. Monitor these diseases and the control program } \\
\text { 2. Perform studies for awareness and advocacy } \\
\text { 3. Peform activities for prevention of the development of disease } \\
\text { 4. Perform activities for early detection and prevention of progress } \\
\text { 5. Provide effective treatment and prevent complications }\end{array}$ \\
\hline
\end{tabular}

VIETNAM Expansion of the asthma and COPD outpatient care units to the whole country 
Handling editors Sundeep Salvi and Paul Stephenson

Conflicts of interest The authors declare that they have no conflicts of interest in relation to this article.

\section{References}

1. Action Plan of the Global Alliance Against Chronic Respiratory Diseases, 20082013, @ World Health Organization 2008, ISBN 9789241597203.

2. World Health Organization World Health Report 2004; Changing History. Geneva: World Health Organization,2004

3. GARD Book Global Surveillance, Prevention and Control of Chronic Respiratory Diseases: A Comprehensive Approach.ISBN 9789241563468 (NLM Classification: WF140) ( ) World Health Organization 2007

4. Laurendi G, Mele S, Centanni S, et al. Global alliance against chronic respiratory diseases in Italy (GARD-Italy): strategy and activities. Respir Med. 2012;106(1):1-8. http://dx.doi.org/10.1016/j.rmed.2011.10.0022. Epub 2011 Oct 22
5. Yorgancioglu $A$, Türktas $H$, Kalayci $O$ et al. The WHO global alliance against chronic respiratory diseases in Turkey (GARD Turkey). Tuberk Toraks 2009;57(4):439-52.

6. Vigilância global , prevenção e controlo das doenças respiratórias crónicas uma abordagem integradora" Editores Jean Bousquet, Nikolai Khaltaev. Direcção Geral da Saúde, Ministério da Saúde de Portugal,2008 -ISBN 978-972-675183-0 and ISBN 978924156346 8(WHO 2007)

7. www. longalliantie.nl

8. Camargos PA, Cruz AA, Bousquet J. Medications to the North, patients to the South. J Bras Pneumol 2009;35(7):615-7. http://dx.doi.org/10.1590/S1806-37132009000700001

9. Yorgancioglu A, Yardim N, Ergün P et al. Integration of GARD Turkey national program with other non-communicable diseases plans in Turkey. Tuberk Toraks 2010;58(2):213-28

10. World Health Organization. GARD General Meeting Report, 9 - 10 July 2012 in St-Petersburg, Russia. [http://www.who.int/gard/publications/en/ assessed on 19 November 2013].

\section{Available online at http://www.thepcrj.org}

